\title{
In situ Mixing of Organic Matter Decreases Hydraulic Conductivity of Denitrification Walls in Sand Aquifers
}

\author{
by Gregory F. Barkle, Louis A. Schipper, Craig P. Burgess, and Brett D.M. Painter
}

\begin{abstract}
In a previous study, a denitrification wall was constructed in a sand aquifer using sawdust as the carbon substrate. Ground water bypassed around this sawdust wall due to reduced hydraulic conductivity. We investigated potential reasons for this by testing two new walls and conducting laboratory studies. The first wall was constructed by mixing aquifer material in situ without substrate addition to investigate the effects of the construction technique (mixed wall). A second, biochip wall, was constructed using coarse wood chips to determine the effect of size of the particles in the amendment on hydraulic conductivity. The aquifer hydraulic conductivity was $35.4 \mathrm{~m} / \mathrm{d}$, while in the mixed wall it was $2.8 \mathrm{~m} / \mathrm{d}$ and in the biochip wall $3.4 \mathrm{~m} / \mathrm{d}$. This indicated that the mixing of the aquifer sands below the water table allowed the particles to re-sort themselves into a matrix with a significantly lower hydraulic conductivity than the process that originally formed the aquifer. The addition of a coarser substrate in the biochip wall significantly increased total porosity and decreased bulk density, but hydraulic conductivity remained low compared to the aquifer. Laboratory cores of aquifer sand mixed under dry and wet conditions mimicked the reduction in hydraulic conductivity observed in the field within the mixed wall. The addition of sawdust to the laboratory cores resulted in a significantly higher hydraulic conductivity when mixed dry compared to cores mixed wet. This reduction in the hydraulic conductivity of the sand/sawdust cores mixed under saturated conditions repeated what occurred in the field in the original sawdust wall. This indicated that laboratory investigations can be a useful tool to highlight potential reductions in field hydraulic conductivities that may occur when differing materials are mixed under field conditions.
\end{abstract}

\section{Introduction}

Denitrification walls are low-cost, permeable, reactive walls designed to remove nitrate from shallow ground water (Robertson et al. 2000; Schipper and VojvodicVukovic 2001). Microbial denitrification, converting nitrate to nitrogen gases, is promoted by mixing a carbon substrate into a shallow aquifer. For denitrification walls to be effective at protecting downstream receiving water, the wall needs to intercept and treat as much of the ground water as possible.

A recent study of a denitrification wall constructed in a sand aquifer ( $18 \%$ by volume of sawdust) found that most of the ground water was bypassing under this sawdust wall (Schipper et al. 2004). Natural gradient tracer tests demonstrated that hydraulic conductivity of the sawdust wall was $0.48 \mathrm{~m} / \mathrm{d}$, whereas the hydraulic conductivity in the surrounding aquifer material was estimated to be $65.4 \mathrm{~m} / \mathrm{d}$. Two potential causes for the loss of conductivity were identified; the added sawdust grains may have filled the pores between the sand grains or alternatively the mixing of the aquifer sand, under wet conditions, may have created a new packing configuration with lower hydraulic conductivity. Both of these causes could have reduced pore connectivity and/or porosity, but potential solutions to these causes differ. If sawdust is blocking the pores, then a larger particle size of added organic matter may maintain conductivity. If the mixing of sand under saturated conditions was the cause, then walls built in sand aquifers such as these need to be constructed once the water table has been lowered or other engineering solutions found to maintain hydraulic conductivity.

In this study, our primary objective was to determine the cause for the decrease in hydraulic conductivity reported by Schipper et al. (2004). Two smaller denitrification walls were constructed at the same site as the initial study. In an attempt to maintain the hydraulic conductivity, in one of these walls we mixed in garden chip (chipped bush and scrub material), a much coarser material than the sawdust-the biochip wall. A second wall had no substrate added and consisted of aquifer material only, mixed in 
situ-the mixed wall. This mixed wall was constructed to determine whether the decrease in hydraulic conductivity was simply due to the mixing of the aquifer sand under saturated conditions. The distributions of the grain sizes in the aquifer and in the original sawdust wall were measured. These distributions were measured to ascertain if sufficient fine-grained silt-sized materials were present in horizontal lenses in the aquifer, which when mixed could have decreased hydraulic conductivity. We monitored ground water nitrate concentrations and determined hydraulic conductivities of both walls and surrounding aquifer using natural gradient tracer tests.

A second objective of this study was to test if laboratory measurements of the saturated hydraulic conductivity of refilled cores mixed with different combinations of organic matter and the aquifer material could be useful to indicate the expected hydraulic performance in the field. The laboratory measures of hydraulic conductivities were compared to the field results from the in situ natural gradient tracer tests. The sand/sawdust cores were mixed under saturated and dry conditions. Wet mixing mimicked the construction technique used in the field for the sawdust, biochip, and mixed walls, whereas dry mixing mimicked a dewatering construction technique.

The third objective of the work was to ascertain if either effective or total porosity is a better parameter to relate to the hydraulic performance of the materials being considered for denitrification walls. Effective porosity is defined as the ratio of the pore space, through which flow can occur, to the total volume (Bear 1972; Fetter 1980). It is determined from the total porosity minus the water content at field capacity (33 kPa) (Ahuja et al. 1984; Timlin et al. 1999; Suleiman and Ritchie 2001). Field capacity is the soil water content of a soil remaining in a soil 2 or $3 \mathrm{~d}$ after having been wet with water, and free drainage becomes practically negligible (Suleiman and Ritchie 2001). The term effective porosity can also be called specific yield or drainable porosity (Bear 1972; Ritzema 1994).

\section{Methods}

\section{Construction of Biochip and Mixed Walls}

The biochip and mixed wall were both constructed at the same site and in the same manner as the original sawdust wall described by Schipper et al. (2004). Both walls were $20 \mathrm{~m}$ long, $3 \mathrm{~m}$ wide, and $3 \mathrm{~m}$ deep. An excavator with a 2-m wide bucket removed the topsoil down to $0.3 \mathrm{~m}$ over a 3-m wide strip. The underlying sand was then removed down to the water table (approximately $1 \mathrm{~m}$ from original ground level) and stockpiled on the side of the trench. Fifty cubic meters of biochip material was then placed in the trench and the excavator bucket used to mix the biochip with the aquifer sand down to $3 \mathrm{~m}$ (i.e., $2 \mathrm{~m}$ into the water table). At times, it was necessary to lift material out of the trench to provide the excavator space for the mixing process. This mixed material was later placed back in the trench. The topsoil was returned to the top of the trench once the sand and biochip were thoroughly mixed. The biochip material included leaves, twigs, and branches that had been shredded to chips less than $1 \mathrm{~cm}$ in length.

The mixed wall had no organic substrate added, and the aquifer material was mixed in the same manner as described previously. From cone penetrometer measurements (Geoprobe Systems, Salina, Kansas), a silty/clay aquiclude was identified at approximately $8 \mathrm{~m}$ depth, so that the 3-m deep walls penetrated $30 \%$ of the shallow water table aquifer.

\section{Physical Characteristics of the Walls and Aquifer}

Total porosity of the aquifer, biochip, and mixed walls was calculated from bulk density and particle density measurements (McLaren and Cameron 1990) using in situ cores $(103 \mathrm{~mm}$ diameter $\times 50 \mathrm{~mm}$ high) taken from a depth of $1 \mathrm{~m}$. Particle density was calculated using a water displacement method (Gradwell and Birrell 1979). The uniformity coefficient $C_{\mathrm{u}}$ of the particle size distribution, which is used to infer the behavior of hydraulic conductivity, was calculated from the ratio of the grain size below which $60 \%$ of the sample is finer than (i.e. $\mathrm{D}_{60}$ ) to the grain size below which $10 \%$ of the sample is finer than (i.e. $\mathrm{D}_{10}$ ).

\section{Ground Water Monitoring}

Polyvinyl chloride pipes (PVC) $(15 \mathrm{~mm}$ nominal diameter) with $0.45-\mathrm{mm}$ wide slots over their entire length were used to monitor ground water nitrate concentrations. Six ground water monitoring wells ( $2.5 \mathrm{~m}$ deep) were installed around each of the walls (Figure 1). Two wells were located $1 \mathrm{~m}$ in front of the upstream face of the wall, two at midpoint in the wall, and two $1 \mathrm{~m}$ downstream of the wall. Wells were installed using a direct push-probe system (Geoprobe, Salina, Kansas). This procedure involved driving a $40-\mathrm{mm}$ torpedo probe down to the required depth using a percussion hammer, jacking the probe out of the

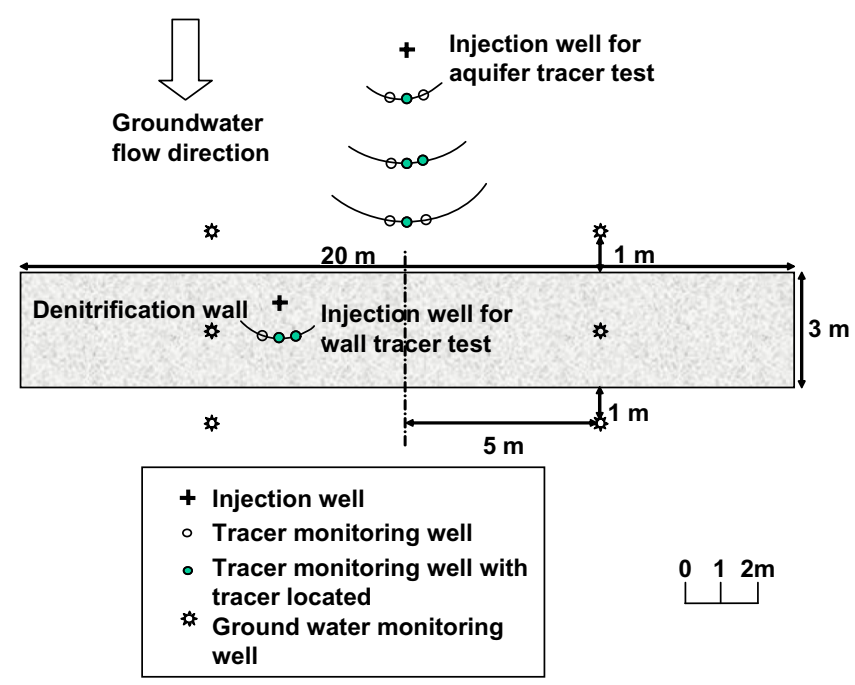

Figure 1. Location of ground water and natural gradient tracer monitoring wells for the biochip wall. Injection well is $6.0 \mathrm{~m}$ away from the wall. The third arc of tracer monitoring wells is $\mathbf{4} \mathbf{~ m}$ from the injection well for the biochip wall and $5 \mathrm{~m}$ for the mixed wall. 
ground, and quickly inserting the PVC monitoring well down the hole. Subsequent pumping of the well until the water became clear developed the monitoring well.

Monitoring wells were purged to remove at least two well volumes before a $60-\mathrm{mL}$ ground water sample was collected. Samples were chilled in the field and then frozen prior to analysis in the laboratory for $\mathrm{NO}_{3}$ concentrations using standard autoanalyser techniques (Blakemore et al. 1987). Samples were collected 49, 79, 140, and $196 \mathrm{~d}$ after construction of the walls.

\section{Natural Gradient Tracer Tests}

Two natural gradient tracer tests were conducted within each wall (test A and B) and also in the aquifer upstream from the two walls to determine the in situ hydraulic conductivities. The injection and monitoring wells were the same type and installed using the same procedure as for the ground water nitrate monitoring wells.

An arc of three monitoring wells, $0.8 \mathrm{~m}$ away from the injection well and $0.3 \mathrm{~m}$ apart from each other, was installed within both walls (Figure 1). Two liters of tracer (3000 $\mu \mathrm{g} / \mathrm{mL} \mathrm{KBr}$ and $2500 / \mu \mathrm{g} \mathrm{mL}$ of Rhodamine WT) were injected slowly over $40 \mathrm{~min}$ into each injection well. An audio water level meter was used in the injection well to ensure that the tracer did not induce ground water mounding. The tracer was injected using a $60-\mathrm{mL}$ hypodermic syringe connected to $3 \mathrm{~m}$ of small nylon tube $(5 \mathrm{~mm}$ diameter). The delivery tube was sealed on the end and had pinholes in the lower $1.5 \mathrm{~m}$. The Rhodamine WT tracer allowed visual observation to be made of the direction of the plume in the field. This allowed improved sampling schedules and better location of additional monitoring wells to be installed as required.

Ground water samples were taken from monitoring wells $24 \mathrm{~h}$ after tracer injection, and subsequently at approximately 12 hourly intervals until the breakthrough curves were complete. To collect a sample, two well volumes were purged from each monitoring well and a $60-\mathrm{mL}$ sample was collected into a sterile $70 \mathrm{~mL}$ bottle using a hypodermic syringe with a 3 -m-long nylon tube $(5 \mathrm{~mm}$ diameter) attached. Depth to the water table was measured using an audio water level meter before ground water samples were collected. The level of each monitoring well was accurately determined with survey equipment.

Injection wells for the aquifer tests $(15 \mathrm{~mm}$ nominal diameter, PVC) were installed $6 \mathrm{~m}$ upgradient of the biochip and mixed wall (Figure 1) for determination of aquifer hydraulic conductivities. Arcs of three monitoring wells were installed at $0.75,1.5 \mathrm{~m}$, and either $4 \mathrm{~m}$ (biochip wall) or $5 \mathrm{~m}$ (mixed wall) from the injection wells. The same methodology and equipment used in the wall tracer tests were used, except that $20 \mathrm{~L}$ of tracer were injected in 120 min without ground water mounding.

Bromide concentrations in all well samples were measured using an ion selective electrode (Metrohm 6.0502.100, Switzerland). The probe was calibrated with standards covering the range of the measurements using the method of Abdalla and Lear (1975). The Rhodamine WT was measured using a spectrofluorimeter (Turner model 112) with an emission wavelength of $590 \mathrm{~nm}$, an excitation wavelength of $546 \mathrm{~nm}$, and a slit number of 30 .

\section{Hydraulic Conductivity of Laboratory Cores}

Hydraulic conductivity was measured using a constant head permeameter on large (200-mm-diameter $\times 900$ mm-long PVC pipes) repacked cores of aquifer sand with $0 \%, 10 \%$, or $20 \%$ (by volume) of sawdust added. The aquifer sand was collected from the site where the walls were installed. The same sawdust as used in the original sawdust wall (Schipper et al. 2004) was used in the laboratory experiments. The appropriate amount of sawdust was premixed thoroughly with the air-dried aquifer sand. The PVC tubes were either filled with the sand/sawdust mixture with water to simulate the construction technique used in the field, or filled dry to simulate construction conditions as if the ground water was lowered. The sand/sawdust cores mixed under saturated conditions were constructed by adding the premixed, air-dried, sand-sawdust mixture to water in the PVC tube in approximately $3.5-\mathrm{kg}$ increments. Further agitation, under water, was applied to the cores by shaking the tubes to simulate the action of the excavator bucket as used in the field. The inside of the PVC tubes had a thin layer of sand attached using wax to prevent preferential flow down the edge of the repacked cores. The flow rate of the water through the cores was measured until steady-state conditions were achieved. The head loss gradient through the cores was measured on individual runs and was approximately $0.28 \mathrm{~m} / \mathrm{m}$.

\section{Physical Characteristics of the Laboratory Cores}

Bulk density for each laboratory core was determined either from three cores (51.4 $\mathrm{mm}$ diameter $\times 50 \mathrm{~mm}$ high) taken from within the larger soil core or the total soil core volume used. Total porosity and particle density were measured as discussed previously. The effective porosity of each core was determined from the volume of water draining completely under gravity from an initially saturated core, divided by the total volume of the core (Fetter 1980; Suleiman and Ritchie 2001).

\section{Statistical Analysis}

Analysis of variance (ANOVA) of the physical properties and hydraulic conductivities of the soil cores, aquifer, and walls were completed using either a one-way or twoway ANOVA (SYSTAT 9, SPSS Inc., Illinois). Post hoc tests using Bonferroni analysis subsequently tested pairwise comparisons where appropriate. Linear regression was performed using LINEST, in Excel (Microsoft USA, Redmond, MA). Unless stated otherwise, results are presented as average \pm 1 standard error and considered significance at 0.05 level.

\section{Results}

\section{Ground Water $\mathrm{NO}_{3}$ Concentrations}

The $\mathrm{NO}_{3}$ concentration measured four times over 6 months in the monitoring wells around and within the 
biochip wall showed a slight nonsignificant reduction between upstream and downstream values. Averaged over the samplings, the $\mathrm{NO}_{3}$ concentration upstream of the wall was $43.2 \pm 4.0 \mathrm{mg} \mathrm{N} / \mathrm{L}$, in the wall $0.16 \pm 0.11 \mathrm{mg} \mathrm{N} / \mathrm{L}$, and downstream of the wall $37.3 \pm 1.3 \mathrm{mg} \mathrm{N} / \mathrm{L}$. This result is similar to the original sawdust wall (Schipper et al. 2004).

As expected, given that no carbon substrate was added, there was no $\mathrm{NO}_{3}$ removal in the mixed wall. Average $\mathrm{NO}_{3}$ concentrations upstream of the mixed wall, within the mixed wall, and downstream were $40.6 \pm 1.7,42.1 \pm 1.8$, and $42.0 \pm 1.8 \mathrm{mg} \mathrm{N} / \mathrm{L}$, respectively.

\section{Natural Gradient Tracer Tests}

Hydraulic conductivities were calculated using the bromide data (Table 1). It was assumed that the centroid of the bromide plume was moving at the average linear ground water velocity regardless of the effects of dispersivity or flow geometry. The centroid of the Rhodamine WT plume was not used as it was retarded compared to the bromide centroid (Figure 2). Others (Goel 1994; Brown et al. 2001; Schipper et al. 2004) have also reported similar retardation of Rhodamine WT. The estimated effective porosities for the determination of the hydraulic conductivity were based on the measured total field porosities and the laboratory ratios of the effective to total porosities. The ratio from the aquifer sand cores ( 0.56 of total porosity) was assumed to represent the aquifer. The biochip wall was assumed to have an effective porosity of 0.38 of total porosity based on the average of the wet mixed sand/sawdust cores. The mixed wall was based on the wet mixed sand cores ( 0.56 of total porosity). The average hydraulic conductivity from the natural gradient tests within the biochip wall was $3.4 \pm$ $1.2 \mathrm{~m} / \mathrm{d}$ and in the mixed wall $2.8 \pm 0.5 \mathrm{~m} / \mathrm{d}$, which were not significantly different (Table 1). The mean hydraulic conductivity of the aquifer $(35.4 \pm 5.8 \mathrm{~m} / \mathrm{d})$ was significantly higher than both these values.

\section{Physical Characteristics of the Walls and Aquifer}

The total porosities of the mixed wall and aquifer were the same and both significantly less than that of the biochip wall (Table 2). The greater porosity in the biochip wall was attributed to the addition of the wood chip material decreasing the bulk density compared to that of the mixed wall and aquifer.

The particle size distributions in the aquifer and the sawdust wall were both well-sorted distributions with the $C_{\mathrm{u}}$ being less than 4.0 (aquifer sand 3.0, sawdust wall 2.8; Figure 3 ). The aquifer material has only $1.4 \%$ of particles in the silt size range, with $87.4 \%$ being sand-sized class materials (Table 3). With the addition of sawdust to the aquifer material to construct the sawdust wall, the fine siltsized fraction dropped to only $0.4 \%$ and the sand fraction to $81.0 \%$.

\section{Table 1}

Time for Centroid of Tracer Plume to Pass Observation Wells for the Two Tracer Tests within the Biochip and Mixed Walls and the Single Aquifer Tracer Test, Pore Velocity, Hydraulic Gradient, and Hydraulic Conductivity $(\mathrm{m} / \mathrm{d})$ within Walls and Aquifer

\begin{tabular}{|c|c|c|c|c|c|}
\hline Location & Distance (m) & $\begin{array}{l}\text { Time to Centroid } \\
\text { of Bromide (h) }\end{array}$ & $\begin{array}{c}\text { Bromide } \\
\text { Pore Velocity }(\mathrm{m} / \mathrm{d})\end{array}$ & $\begin{array}{c}\text { Hydraulic } \\
\text { Gradient }(\mathbf{m} / \mathbf{m})\end{array}$ & $\begin{array}{c}\text { Hydraulic } \\
\text { Conductivity }(\mathrm{m} / \mathrm{d})\end{array}$ \\
\hline \multicolumn{6}{|l|}{ Within biochip wall } \\
\hline Test A & 0.8 & 188.1 & 0.10 & 0.021 & 1.0 \\
\hline \multirow{2}{*}{ Test B } & 0.8 & 58.1 & 0.33 & 0.016 & 4.4 \\
\hline & 0.8 & 61.5 & 0.31 & 0.014 & 4.7 \\
\hline \multirow[t]{2}{*}{ Test A } & 0.8 & 88.2 & 0.22 & 0.019 & 2.5 \\
\hline & 0.8 & 63.0 & 0.31 & 0.018 & 3.7 \\
\hline \multirow[t]{2}{*}{ Test B } & 0.8 & 42.1 & 0.46 & 0.030 & 3.3 \\
\hline & 0.8 & 82.9 & 0.23 & 0.025 & 2.0 \\
\hline Average (standard error) & & & & & $2.8^{\mathrm{a}}(0.5)$ \\
\hline \multicolumn{6}{|l|}{ Aquifer tracer test } \\
\hline \multirow[t]{4}{*}{ Upstream of mixed wall } & 0.8 & 31.5 & 0.57 & 0.010 & 12.4 \\
\hline & 1.5 & 32.1 & 1.12 & 0.008 & 30.6 \\
\hline & 1.5 & 40.1 & 0.90 & 0.005 & 39.3 \\
\hline & 5.0 & 69.5 & 1.73 & 0.006 & 63.0 \\
\hline Average (standard error) & & & & & $35.4^{\mathrm{b}}(5.8)$ \\
\hline
\end{tabular}




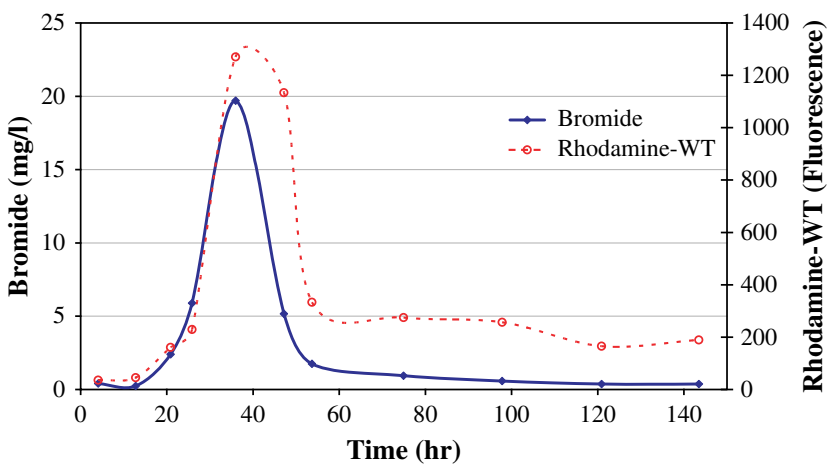

Figure 2. Example of breakthrough curves from the natural gradient tracer test in an observation well $1.5 \mathrm{~m}$ from the injection well upstream of the mixed wall. Centroid of the Rhodamine WT (----) tracer is retarded compared to that of the bromide (-).

\section{Hydraulic Conductivities of the Laboratory-Mixed Cores}

The hydraulic conductivities of the sand/sawdust cores were significantly lower when they were mixed under wet conditions as compared with dry (Figure 4). With increasing the proportion of sawdust, only the hydraulic conductivity of the dry mixed cores increased. However, due to high variability, this increase $(99.5$ to $128.7 \mathrm{~m} / \mathrm{d}$ ) was not significant.

The hydraulic conductivity of the sand cores when mixed dry was $71.3 \pm 20.9 \mathrm{~m} / \mathrm{d}$, which decreased, but not significantly again due to the high variability, to $25.5 \pm$ $11.1 \mathrm{~m} / \mathrm{d}$ when mixed wet (Table 4).

\section{Physical Properties of the Laboratory Cores}

The average total porosity of all dry mixed cores was significantly higher than the overall average of the wet mixed cores. Independent of the mixing method, the addition of sawdust (10\% or $20 \%)$ increased the total porosities significantly compared to the sand cores. Total porosities were significantly different only between the dry and the wet mixing in the sand cores (Table 4).

The effective porosities of the sand cores mixed either wet or dry were not significantly different. However, there was a significant difference in effective porosity between wet and dry mixing with the addition of sawdust. Increasing the amount of sawdust from $10 \%$ to $20 \%$ did not increase the effective porosity of the cores. The average effective porosity of the dry mixed sand/sawdust cores was

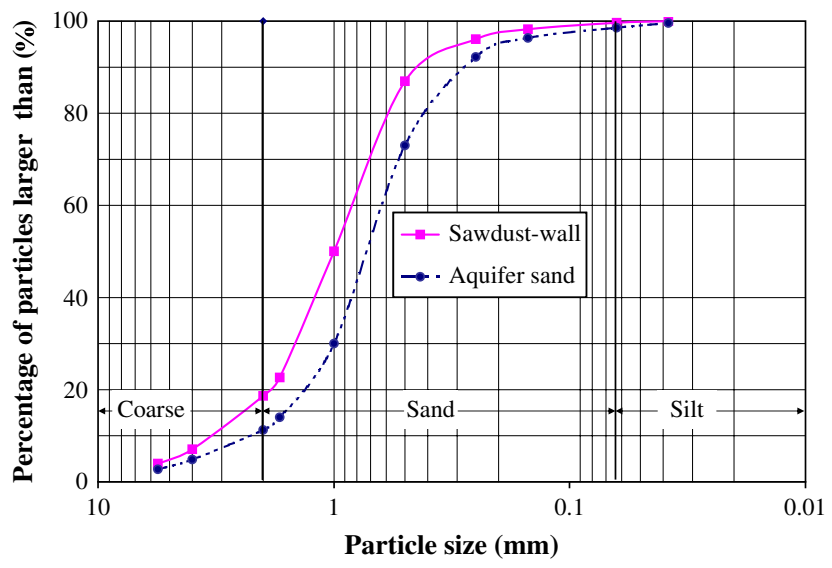

Figure 3. Particle size distribution for the sawdust wall and in the aquifer sand.

approximately $58 \%$ of the total porosity. In the wet mixed sand/sawdust cores, the effective porosity was only $38 \%$ of the total porosity.

The effective porosity was a better predictor $\left(R^{2}=\right.$ 0.91 , standard deviation of the residuals $=17.2$ ) of the hydraulic conductivity of the laboratory cores than the total porosity $\left(R^{2}=0.56\right.$, standard deviation of the residuals $=$ 37.1; Figure 5).

\section{Discussion}

The large decreases in the hydraulic conductivities and the nitrate monitoring data suggested that ground water was bypassing under and around both the biochip and the mixed walls. The reduction in hydraulic conductivity of the mixed wall supports the hypothesis that it was the mixing technique used in construction of the original sawdust wall and not the addition of organic material that reduced conductivity. The addition of coarse organic material, as in the biochip wall, while increasing the total porosity $(0.56$ compared to 0.38 ) did not significantly increase the hydraulic conductivity above that of the mixed wall $(3.4 \mathrm{~m} / \mathrm{d}$ compared to $2.8 / \mathrm{m} \mathrm{d}$ ).

The aquifer and the sawdust wall have only $1.4 \%$ and $0.4 \%$ of silt-sized particles present, respectively. This result indicated that there was not a large amount of silt present in horizontal layers within the undisturbed aquifer that could be redistributed during the in situ mixing process. Such a redistribution of finer grained materials could

\section{Table 2}

Physical Properties of the Biochip Wall, Mixed Wall, and the Aquifer Sand Using in situ Cores

\begin{tabular}{|c|c|c|c|c|c|c|}
\hline \multirow[b]{2}{*}{ Location } & \multirow[b]{2}{*}{$n$} & \multicolumn{2}{|c|}{ Bulk Density $\left(\mathrm{g} \mathrm{cm}^{-3}\right)$} & \multicolumn{2}{|c|}{ Particle Density $\left(\mathrm{g} \mathrm{cm}^{-3}\right)$} & \multirow{2}{*}{$\frac{\text { Total Porosity }(-)}{\text { Mean }}$} \\
\hline & & Mean & Standard Error & Mean & Standard Error & \\
\hline Biochip wall & 10 & $1.10^{\mathrm{a}}$ & 0.03 & $2.51^{\mathrm{a}}$ & 0.01 & $0.56^{\mathrm{a}}$ \\
\hline Mixed wall & 10 & $1.65^{\mathrm{b}}$ & 0.01 & $2.66^{\mathrm{b}}$ & 0.00 & $0.38^{\mathrm{b}}$ \\
\hline Aquifer & 8 & $1.64^{\mathrm{b}}$ & 0.02 & $2.70^{\mathrm{c}}$ & 0.01 & $0.39^{\mathrm{b}}$ \\
\hline
\end{tabular}




\begin{tabular}{|lcc|}
\hline \multicolumn{3}{|c|}{ Table 3} \\
Percentage of Particles in Coarse, Sand, and Silt Size \\
Fractions in the Aquifer and in the Sawdust Wall \\
\hline Particle Size Class & Sawdust Wall (\%) & Aquifer (\%) \\
\hline Coarse $>2 \mathrm{~mm}$ & 18.6 & 11.2 \\
$63 \mu \mathrm{m}<$ Sand $<2 \mathrm{~mm}$ & 81.0 & 87.4 \\
Silt $<63 \mu \mathrm{m}$ & 0.4 & 1.4 \\
\hline
\end{tabular}

result in a reduction in hydraulic conductivity. Rather, it appeared that particle sizes in the aquifer repacked into a new configuration when mixed under saturated conditions. Consequently, the hydraulic conductivity was reduced in the mixed wall in comparison to the natural aquifer. This result was supported by the reduction in the hydraulic conductivities in the sand/sawdust cores mixed wet as compared to those mixed dry.

Our laboratory data predict a very large (87\%) reduction in hydraulic conductivity for a denitrification wall constructed under saturated conditions with $18 \%$ sawdust such as constructed by Schipper et al. (2004). This predicted level of reduction in hydraulic conductivity would be sufficient to alert a designer of such a system that the proposed mixture of materials and method of construction would not result in a hydraulically functioning denitrification wall. Gavaskar et al. (1998) showed that when the ratio of the $K_{\text {gate }} / K_{\text {aquifer }}$ drops to 0.14 , the relative flow through the permeable reactive barrier drops to only $29 \%$ of that through an unrestricted system.

The hydraulic conductivities measured in the laboratory were derived without the effect of any overburden material being considered. It could be expected that overburden would probably result in compaction in the laboratory cores causing a decrease in hydraulic conductivity. Further work is needed to determine the magnitude of this reduction. This reduction in hydraulic conductivity would probably be greater in the sand/sawdust cores mixed dry, as compared to the wet mixed cores, because the dry mixed cores have a lower bulk density and hence be more susceptible to the effects of compaction due to the overburden. Additionally, the wet mixed cores were vibrated and mixed thoroughly to

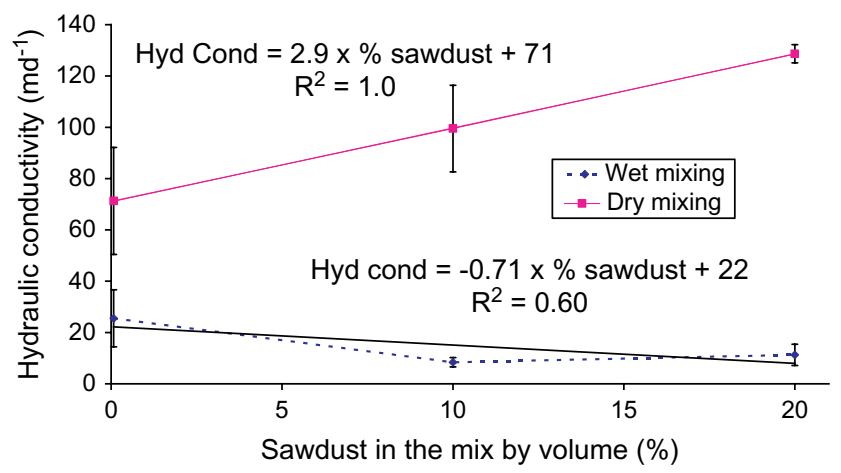

Figure 4. Hydraulic conductivity $(\mathrm{m} / \mathrm{d})$ of sand-sawdustmixed cores with increasing amounts of sawdust, mixed either dry or wet. Error bars are \pm 1 standard error.

simulate the field construction conditions; this probably promoted greater compaction in these treatments.

The success of the laboratory investigations to reproduce the trends in hydraulic conductivity observed in the field suggests that this type of investigation is a useful to tool to help predict relative but not absolute hydraulic conductivities of denitrification walls constructed of various materials.

Effective porosity was a better parameter to relate to hydraulic conductivity than total porosity. However, the robustness and applicability of the empirical relationship derived applies only to the narrow range of material tested. There is still the need to test this relationship over a significantly wider range of aquifer materials, organic substrates, and mixing conditions to confirm its general applicability.

While hydraulic conductivities and effective porosities of sand/sawdust cores mixed wet and dry were significantly different, the total porosities were not different. Total porosity was not a good predictor of hydraulic performance probably because this measure includes pores that are not connected and do not contribute to flow. Additionally, some of the water contained in the total pore space is held so tightly to the soil surface by surface tension forces that it cannot contribute to flow. That total porosity is a poor predictor of hydraulic conductivity agrees with other studies (e.g., Fetter 1980). However, effective porosity has been shown to be a good predictor of hydraulic conductivity; for

\begin{tabular}{|c|c|c|c|c|c|c|}
\hline \multicolumn{7}{|c|}{$\begin{array}{l}\text { Table } 4 \\
\text { Average (Standard Error) of Hydraulic Conductivity, Total Porosity, Effective Porosity, and Bulk Density } \\
\text { for Laboratory Cores Mixed Either Dry or Wet with Increasing Amounts of Sawdust in the Mix }\end{array}$} \\
\hline & \multicolumn{6}{|c|}{ Ratio of Volume Sand:Sawdust in Cores } \\
\hline & \multicolumn{2}{|c|}{ Aquifer Sand Only } & \multicolumn{2}{|c|}{ 10:1 } & \multicolumn{2}{|c|}{$20: 1$} \\
\hline & $\begin{array}{c}\text { Dry Mixed } \\
(n=6)\end{array}$ & $\begin{array}{c}\text { Wet Mixed } \\
(n=6)\end{array}$ & $\begin{array}{c}\text { Dry Mixed } \\
(n=3)\end{array}$ & $\begin{array}{c}\text { Wet Mixed } \\
(n=3)\end{array}$ & $\begin{array}{c}\text { Dry Mixed } \\
\quad(n=3)\end{array}$ & $\begin{array}{c}\text { Wet Mixed } \\
\quad(n=3)\end{array}$ \\
\hline Hydraulic conductivity (m/d) & $71.3^{\mathrm{a}}(20.9)$ & $25.5^{\mathrm{a}}(11.1)$ & $99.5^{\mathrm{a}}(16.9)$ & $8.4^{\mathrm{b}}(1.8)$ & $128.7^{\mathrm{a}}(3.6)$ & $11.3^{\mathrm{b}}(4.2)$ \\
\hline Total porosity $(-)$ & $0.45^{\mathrm{a}}(0.01)$ & $0.41^{\mathrm{b}}(0.01)$ & $0.55^{\mathrm{a}}(0.02)$ & $0.51^{\mathrm{a}}(0.01)$ & $0.56^{\mathrm{a}}(0.01)$ & $0.53^{\mathrm{a}}(0.00)$ \\
\hline Effective porosity (-) & $0.25^{\mathrm{a}}(0.01)$ & $0.23^{\mathrm{a}}(0.01)$ & $0.32^{\mathrm{a}}(0.01)$ & $0.19^{\mathrm{b}}(0.00)$ & $0.32^{\mathrm{a}}(0.01)$ & $0.21^{\mathrm{b}}(0.01)$ \\
\hline Bulk density $\left(\mathrm{g} \mathrm{cm}^{-3}\right)$ & $1.48(0.03)$ & $1.60(0.03)$ & $1.21(0.06)$ & $1.31(0.02)$ & $1.17(0.02)$ & $1.23(0.01)$ \\
\hline
\end{tabular}




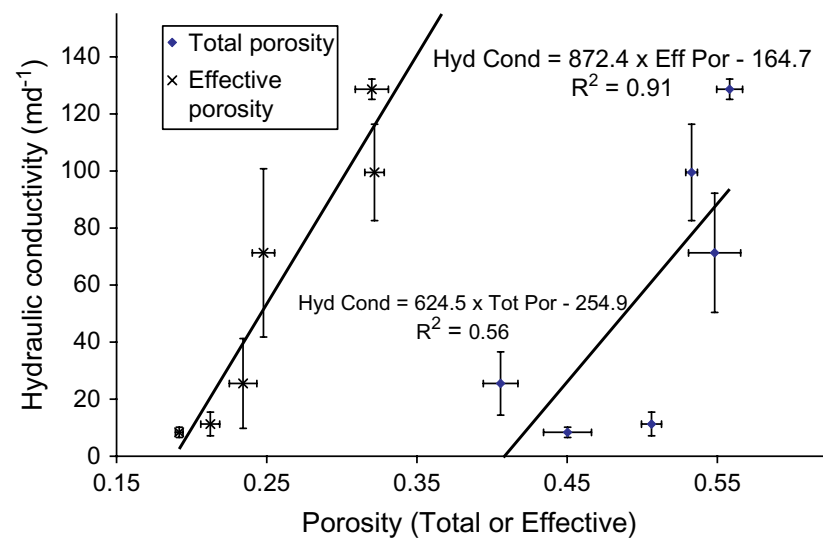

Figure 5. Effective or total porosity vs. hydraulic conductivity $(\mathrm{m} / \mathrm{d})$ of laboratory cores. Error bars are \pm 1 standard error.

example, Ahuja et al. (1989), Franzmeier, (1991), Timlin et al. (1999), and Aimrun et al. (2004).

Field hydraulic conductivities were determined from the natural gradient tracer tests using the measured linear ground water velocities, hydraulic gradients, and estimated effective porosities based on ratios from the laboratory core studies. Like all field tracer tests, we do not have in situ measurements of effective porosity because no technique is available for measurement of this parameter under field conditions. To improve the estimation of hydraulic conductivity from field tracer studies, further work is required in determining effective porosity in situ.

\section{Implications}

Construction of denitrification walls by mixing the carbon substrate in situ under saturated conditions is unsuitable in coarse sand aquifers. A preferred technique where the subsoil is removed from the trench mixed with the carbon substrate and then returned into the trench (Schipper and Vojvodic-Vukovic 1998). This construction technique requires the walls of the trench to remain open, and at sites with coarse subsoils keeping the walls stable could be met by either dewatering or sheet piling (Lindahl and Warrington 2005) or the use of guar-based slurry (Calvin et al. 2005) that is displaced upon trench filling. While these options are feasible, they add significantly to the construction costs. Denitrification walls built in this manner may no longer meet their objective of being a cheap treatment option for shallow ground water nitrate removal. The construction of permeable reactive barriers for treatment of pollutants of higher environmental impact can easily justify additional costs of construction.

\section{Acknowledgments}

We are deeply indebted to our former colleague Craig Burgess, who was in charge of the fieldwork for this project. The staff from Hautapu Dairy Factory, Fonterra Ltd., are thanked for their assistance in establishing the site. We thank John Hadfield for his loan of equipment for the natural gradient tracer tests, Donna Grimshaw for her assistance in the fieldwork, Dr. Neil Cox for his advice on statistical analysis, and assistance with laboratory measurements by the late John Milne and Geoffrey Warren. We thank Dr. Roland Stenger, Dr. Fuli Wang, Ms. Pauline Hunt, and two anonymous reviewers for their inputs in to this manuscript. This work was funded under New Zealand Foundation for Research Science and Technology contracts numbers LVLX0204 and C09X0017.

\section{References}

Abdalla, N.A., and B. Lear. 1975. Determination of inorganic bromide in soils and plant tissues with a bromide selective-ion electrode. Communications in Soil and Plant Analysis 6, 489-494.

Ahuja, L.R., J.W. Naney, R.E. Green, and D.R. Nielsen. 1984. Macro-porosity to charactersize spatial variability of hydraulic conductivity and effects of land management. Soil Science Society of America Journal 48, no. 4: 699-702.

Ahuja, L.R., D.K. Cassel, R.R. Bruce, and B.B. Barnes. 1989. Evaluation of spatial distribution of hydraulic conductivity using effective porosity data. Soil Science Society of America Journal 148, no. 6: 404-411.

Aimrun, W., M.S.M. Amin, and S.M. Eltib. 2004. Effective porosity of paddy soils as an estimation of its saturated hydraulic conductivity. Geoderma 121, no. 3-4: 197-203.

Bear, J. 1972. Dynamics of Fluids in Porous Media. New York: Elsevier.

Blakemore, L.C., P.L. Searle, and B.K. Daly. 1987. Methods for chemical analysis of soils. Scientific Report 80. Lower Hutt, New Zealand: NZ Soil Bureau.

Brown, M.T., M.D. Annable, J.J. Delfino, J.W. Jawitz, M. Cohen, and E. Hall. 2001. Determination of an appropriate onsite sewage system setback distance to seasonally inundated areas. Tallahassee, Florida: Florida Department of Health.

Calvin, C., I. Hilary, and G. Lorne. 2005. Barrier Systems for Environmental Contaminant Containment and Treatment. Boca Raton, FL: CRC Press. ISBN: 0849340403.

Fetter, C.W. Jr. 1980. Applied Hydrogeology. Columbus, Ohio: Charles E. Merrill Publishing Co. ISBN: 0-675-08126-2.

Franzmeier, D.P. 1991. Estimation of hydraulic conductivity from effective porosity data for some Indiana soils. Soil Science Society of America Journal 55, no. 6: 1801-1803.

Gavaskar, A.R., N. Gupta, B.M. Sass, R.J. Janosy, D. O'Sullivan. 1998. Permeable Barriers for Groundwater RemediationDesign, Construction, and Monitoring. Columbus, Ohio: Battelle Press. P176 ISBN: 1-57477-036-5.

Goel, S. 1994. Understanding Groundwater Flow Through a Constructed Fen in the Beavercreek Wetlands, Dayton, Ohio. Dayton, Ohio: Wright State University.

Gradwell, M.W., and K.S. Birrell. 1979. Soil Bureau laboratory methods C. Methods for physical analysis of soils. Report 10C. Lower Hutt, New Zealand: NZ Soil Bureau.

Lindahl, H., and D.C. Warrington. 2005. Sheet Pile Design by Pile Buck. Vero Beach, Florida: Pile Buck Inc.

McLaren, R.G., and K.C. Cameron. 1990. Soil Science-An Introduction to the Properties and Management of New Zealand Soils. Auckland, New Zealand: Oxford University Press.

Ritzema H.P. 1994. Drainage Principles and Applications. Wageningen, The Netherlands: International Institute for Land Reclamation and Improvement.

Robertson, W.D., D.W. Blowes, C.J. Ptacek, and J.A. Cherry. 2000. Long-term performance of in situ reactive barriers for nitrate remediation. Groundwater 38, no. 5: 689-695.

Schipper L.A., and M. Vojvodic-Vukovic. 2001. Five years of nitrate removal, denitrification and carbon dynamics in a denitrification wall. Water Research 35, no. 14: 3473-3477. 
Schipper L.A., and M. Vojvodic-Vukovic. 1998. Nitrate removal from ground water using a denitrification wall amended with sawdust. Field trial Journal of Environmental Quality 27, no. 3: 664-668.

Schipper L.A., G.F. Barkle, M. Vojvodic-Vukovic, P.C. Burgess, and J. Hadfield. 2004. Hydraulic constraints on the performance of a groundwater denitrification wall for nitrate removal from shallow groundwater. Journal of Contaminant Hydrology 69, no. 3-4: 263-279.

Suleiman A.A., and J.T. Ritchie. 2001. Estimating saturated hydraulic conductivity from soil porosity. Transactions of ASAE 44, no. 2: 235-239.

Timlin D.J., L.R. Ahuja, Y. Pachepsky, R.D. Williams, D. Gimenez, and W. Rawls. 1999. Use of Brooks-Corey parameters to improve estimates of saturated conductivity from effective porosity. Soil Science Society of America Journal 63, no. 5: 1086-1092.

\section{Biographical Sketches}

Gregory F. Barkle, corresponding author, is a Principal Environmental Engineer and Director at the Aqualinc Research Ltd., P.O. Box 14-041, Enderley, 3252 Hamilton, New Zealand; (64) 7 858 4851; fax (64) 7 858 4847; g.barkle@Aqualinc.co.nz.

Louis A. Schipper is an Associate Professor at the Earth and Ocean Science Department, Waikato University, Private Bag 3105, Hamilton, New Zealand; (64) 7838 4466; fax (64) 7838 4218; L.Shipper@waikato.ac.nz.

*Craig P. Burgess, MSc, Formerly Science Technician at Lincoln Environmental Research, Private Bag 3062, Hamilton, New Zealand.

Brett D.M. Painter is a Research Scientist at Lincoln Environmental Research, P.O. Box 133, Lincoln, Canterbury, New Zealand. (64) 3325 3727; fax (64) 3325 3725; Brett.Painter@lvl.co.nz.

*Deceased author.

\section{(1) Blackwell}

Publishing

\section{Access your journals online}

\section{visit www.blackwell-synergy.com to:}

- Access article abstracts and sample issues for over 800 journals

Read full-text articles through your library subscription

Follow the research with reference links and citing article links

- Register to receive journal tables of contents alerts

- Set up research alerts by keywords, topics, author names or other search terms

Get alerts when an article is cited

And much more.

\section{www.blackwell-synergy.com}

